AC ANNALS JOURNAL CLUB

\title{
The Decline of Maternity Care in Family Medicine
}

Ann Fam Med 2009;7:iii. DOI: 10.1370/afm.965.

$\mathrm{T}$ he Annals of Family Medicine encourages readers to develop a learning community of those seeking to improve health care and health through enhanced primary care. You can participate by conducting a RADICAL journal club and sharing the results of your discussions in the Annals online discussion for the featured articles. RADICAL is an acronym for Read, Ask, Discuss, Inquire, Collaborate, Act, and Learn. The word radical also indicates the need to engage diverse participants in thinking critically about important issues affecting primary care and then acting on those discussions. ${ }^{1}$

\section{HOW IT WORKS}

In each issue, the Annals selects an article or articles and provides discussion tips and questions. We encourage you to take a RADICAL approach to these materials and to post a summary of your conversation in our online discussion. (Open the article online and click on "TRACK Comments: Submit a response.") You can find discussion questions and more information online at: http://www.AnnFamMed.org/AJC/.

\section{CURRENT SELECTION}

\section{Article for Discussion}

Cohen D, Coco A. Declining trends in the provision of prenatal care visits by family physicians. Ann Fam Med. 2009;7(2):128-133.

\section{Discussion Tips}

This article was recommended for discussion by the student and resident members of the Annals Editorial Advisory Board. It includes an analysis of a large nationally representative dataset showing a substantial downward trend in prenatal care by family physicians. The article by $\mathrm{Coco}^{2}$ in this issue may provide some additional useful context for your discussions.

\section{Discussion Questions}

- What question is addressed by the article? How does the question fit with what already is known on this topic?
- How strong are the study design and data source for answering the question?

- To what degree can the findings be accounted for by:

1. How participants were selected?

2. How outcomes were measured?

3. Confounding (false attribution of causality because two variables discovered to be associated actually are associated with a 3rd factor)? 4. Chance?

- What are the main findings? What are the findings of subgroup analyses?

- What do you think of the extrapolation of the findings from 6,203 visits to the entire population?

- What are the implications of the findings for health care policy? At what level are policy changes needed (local, state, nationali personal, by professional organizations and/or government)?

- How do the findings of the study by $\mathrm{Coco}^{2}$ (also in this issue of the Annals) affect your interpretation of the policy implications?

- What are the implications for the field of family medicine?

- What are the implications of the findings for your training and practice plans? (Do you want to zig when many are zagging, or go with the trend?)

- What creative solutions do you see for meeting the maternity care needs of underserved women?

- What are some action next steps for you and other leaders and policy makers based on this study?

\section{References}

1. Stange KC, Miller WL, McLellan LA, et al. Annals Journal Club: It's time to get RADICAL. Ann Fam Med. 2006;4(3):196-197. http:// annfammed.org/cgi/content/full/4/3/196.

2. Coco A. How often do physicians address other medical problems while providing prenatal care? Ann Fam Med. 2009;7(2):134-138. 